\title{
GluA1 Phosphorylation Contributes to Postsynaptic Amplification of Neuropathic Pain in the Insular Cortex
}

\author{
Shuang Qiu, ${ }^{1,2,4}$ Ming Zhang, ${ }^{2,3}$ Yan Liu, ${ }^{3}$ Yanyan Guo, ${ }^{2}$ Huan Zhao, ${ }^{2,3}$ Qian Song, ${ }^{2}$ Minggao Zhao, ${ }^{2}$ Richard L. Huganir, ${ }^{5}$ \\ Jianhong Luo, ${ }^{1} \mathrm{Hui} \mathrm{Xu},{ }^{2,3}$ and Min $\mathrm{Zhuo}^{2,4}$ \\ ${ }^{1}$ Department of Neurobiology, Key Laboratory of Medical Neurobiology of the Ministry of Health of China, Zhejiang University School of Medicine, \\ Hangzhou 310058, China, ${ }^{2}$ Center for Neuron and Disease, Frontier Institutes of Life Science and of Science and Technology, Xi' an Jiaotong University, \\ Xi'an 710049, China, ${ }^{3}$ Institute of Neurosciences, Fourth Military Medical University, Xi' an 710032, China, ${ }^{4}$ Department of Physiology, Faculty of Medicine, \\ University of Toronto, Toronto, Ontario, Canada, M5S 1A8, and 5Department of Neuroscience and Howard Hughes Medical Institute, Johns Hopkins \\ University School of Medicine, Baltimore, Maryland 21205
}

Long-term potentiation of glutamatergic transmission has been observed after physiological learning or pathological injuries in different brain regions, including the spinal cord, hippocampus, amygdala, and cortices. The insular cortex is a key cortical region that plays important roles in aversive learning and neuropathic pain. However, little is known about whether excitatory transmission in the insular cortex undergoes plastic changes after peripheral nerve injury. Here, we found that peripheral nerve ligation triggered the enhancement of AMPA receptor (AMPAR)-mediated excitatory synaptic transmission in the insular cortex. The synaptic GluA1 subunit of AMPAR, but not the GluA2/3 subunit, was increased after nerve ligation. Genetic knock-in mice lacking phosphorylation of the Ser 845 site, but not that of the Ser831 site, blocked the enhancement of the synaptic GluA1 subunit, indicating that GluA1 phosphorylation at the Ser845 site by protein kinase A (PKA) was critical for this upregulation after nerve injury. Furthermore, A-kinase anchoring protein 79/150 (AKAP79/ 150 ) and PKA were translocated to the synapses after nerve injury. Genetic deletion of adenylyl cyclase subtype 1 (AC1) prevented the translocation of AKAP79/150 and PKA, as well as the upregulation of synaptic GluA1-containing AMPARs. Pharmacological inhibition of calcium-permeable AMPAR function in the insular cortex reduced behavioral sensitization caused by nerve injury. Our results suggest that the expression of AMPARs is enhanced in the insular cortex after nerve injury by a pathway involving AC1, AKAP79/150, and PKA, and such enhancement may at least in part contribute to behavioral sensitization together with other cortical regions, such as the anterior cingulate and the prefrontal cortices.

Key words: GluA1; insular cortex; mouse; neuropathic pain; phosphorylation; PKA

\section{Introduction}

Long-term potentiation (LTP) of glutamatergic transmission, the classic experimental model for studying the synaptic mechanism for learning and memory, has been observed in several pain-related sensory central synapses, such as the spinal dorsal horn and the anterior cingulate cortex (ACC; Sandkuhler, 2007, Zhuo, 2008, 2014). In the spinal dorsal horn, LTP can be induced by the typical pairing stimulation (Wei et al., 2006), and periph-

Received April 8, 2014; revised Aug. 26, 2014; accepted Aug. 28, 2014.

Author contributions:S.Q., M. Zhao, J.L., H.X., and M. Zhuo designed research;S.Q., M. Zhang, Y.L., Y.G., H.Z., and Q.S. performed research; H.L.R. contributed unpublished reagents/analytic tools; S.Q., Y.L., Y.G., M. Zhao, and H.X. analyzed data; S.Q., H.X., and M. Zhuo wrote the paper.

This work was supported by Canada Research Chair, Canadian Institute for Health Research Grant 258523, Natural Sciences and Engineering Research Council of Canada Discovery Grant RGPIN 402555, and the Azrieli Foundation and Brain Canada (M.Zhuo). This work was also supported by National Key Basic Research Program of China Grant 2010 CB912002 (J.L.), National Natural Science Foundation of China Grants 30870830 and 31371120 (H.X.) and 81271453 (S.Q.), and Ministry of Education Foundation for Returned Overseas Students Grant HG3503 (H.X.).

Correspondence should be addressed to either of the following: Prof. Min Zhuo, Department of Physiology, University of Toronto, Faculty of Medicine, Medical Science Building, Room 33421 King's College Circle, Toronto, Ontario M5S 1A8, Canada, E-mail:min.zhuo@utoronto.ca; or Prof. Hui Xu, Institute of Neurosciences, Fourth Military Medical University, Xi'an 710032, China, E-mail: xubz@fmmu.edu.cn.

DOI:10.1523/JNEUROSCI.1431-14.2014

Copyright $\odot 2014$ the authors $\quad 0270-6474 / 14 / 3413505-11 \$ 15.00 / 0$ eral injury induces LTP-like enhancement (Ikeda et al., 2006). Cortical LTP has been proposed as a cellular model for chronic pain (Zhuo, 2008). Cingulate synapses undergo persistent changes in the ACC after nerve injury (Xu et al., 2008; Li et al., 2013). Recent studies have revealed the molecular mechanisms of pain-related LTP. Activation of NMDA receptors (NMDARs) is critical for the induction of LTP in the ACC, and the recruitment and modification of AMPA receptors (AMPARs) mediates the expression of pain-related LTP (Zhuo, 2014). Similar findings have been reported in the spinal dorsal horn during acute or persistent inflammatory pain (Galan et al., 2004; Larsson and Broman, 2008; Kopach et al., 2011).

The insular cortex is one other brain region important for pain-related perception (Burkey et al., 1999; Brooks et al., 2005; Harris et al., 2009; Starr et al., 2009; Zhuo, 2011). Human brain imaging studies show that the insular cortex is activated by noxious stimuli (Henderson et al., 2008), and direct electrical stimulation of the insular cortex could elicit painful and somatic sensations, supporting the critical roles of the insular cortex in acute pain and sensory perception (Ostrowsky et al., 2002; Mazzola et al., 2009; Mazzola et al., 2012). At the synaptic level, AMPARs mediate most of the basal excitatory synaptic transmis- 
sion in the insular cortex (Koga et al., 2012). Peripheral nerve injury or tail amputation produces long-term upregulation or activation of the synaptic NMDARs (Zhuo, 1998; Qiu et al., 2013) or loss of long-term depression in the insular cortex (Liu and Zhuo, 2014). In addition, the insular NMDAR-dependent LTP is occluded during neuropathic pain (Qiu et al., 2013). However, little is known about whether AMPAR function undergoes LTP in the insular cortex after peripheral nerve injury.

In this study, we demonstrate that AMPAR function is enhanced in the insular cortex during neuropathic pain. The abundance of synaptic GluA1 was increased, and phosphorylation of GluA1 at the Ser845 site was necessary for the enhancement of synaptic AMPARs. Activation of adenylyl cyclase subtype 1 (AC1) and translocation of A-kinase anchoring protein 79/150 (AKAP79/150) and PKA into the synapse contributed to the enhanced phosphorylation of GluA1. Inhibiting AMPAR function in the insular cortex or genetic dephosphorylation of GluA1 at the Ser845 site reduced behavioral sensitization to non-noxious stimuli of neuropathic pain mice. Together, our results demonstrate that the potentiation of excitatory synaptic transmission is attributable to the enhanced phosphorylation of synaptic GluA1 in the insular cortex during neuropathic pain, and activation of AC1 and translocation of AKAP79/150 and PKA play key roles in the potentiation.

\section{Materials and Methods}

Animals. Adult male C57BL/6 mice (8-12 weeks old) were used in most of the experiments. Mutant male mice lacking $A C 1$ were derived as described previously and bred for several generations (F12-F16) to maintain a C57BL/6 background (Shema et al., 2011). GluA1-S845A and GluA1-S831A gene knock-in lines (genetic background, C57BL/6) were obtained from the laboratory of Dr. Richard Huganir (Johns Hopkins School of Medicine, Baltimore, MD). Mice were housed under a $12 \mathrm{~h}$ light/dark cycle with food and water provided ad libitum. All mouse protocols were in accordance with the National Institutes of Health guidelines and approved by the Animal Care and Use Committee of the University of Toronto.

Neuropathic pain model. A model of neuropathic pain was induced by the ligation of the common peroneal nerve (CPN) as described previously (Vadakkan et al., 2005; Xu et al., 2008). Briefly, the mice were anesthetized by intraperitoneal injection of a saline mixture of ketamine $(0.16 \mathrm{mg} / \mathrm{kg}$; Bimeda-MTC) and xylazine $(0.01 \mathrm{mg} / \mathrm{kg}$; Bayer $)$. The CPN was visible between the anterior and posterior groups of muscles running almost transversely. The left CPN was slowly ligated with a chromic gut suture 5-0 (Ethicon) until contraction of the dorsiflexors of the foot was visible as twitching of the digits. Mechanical allodynia was tested on postsurgical days 3,7 , and 14 . Behavioral experiments were performed blindly, and different individuals were responsible for the surgery and the measurements of the mechanical sensitivity of mice.

Drugs and antibodies. Picrotoxin, tetrodotoxin, protease inhibitor cocktail, and phosphatase inhibitor cocktails 2 and 3 were purchased from Sigma. 6-Cyano-7-nitroquinoxaline-2,3-dione (CNQX) and $N, N, H$,-trimethyl-5-[(tricyclo[3.3.1.13,7] dec-1-ylmethyl)amino]-1pentanaminiumbromide hydrobromide (IEM 1460) were purchased from Tocris Bioscience. Antibodies against GluA1-Ser831 [catalog \#AB5847; 1:1000; Merck; Research Resource Identifier (RRID): AB_11211981], GluA1-Ser845 (catalog \#04-1073; 1:1000; EMD Millipore; RRID: AB_1977219), and GluA2/3 (catalog \#AB1506, 1:2000; EMD Millipore; RRID:AB_90710) were purchased. Antibodies against actin (catalog \#A2066; 1:1000; RRID:AB_476693 or catalog \#A5316; 1:5000; RRID:AB_476743), tubulin (catalog\#T2200; 1:3000;RRID:AB_262133), and synaptophysin (catalog \#S5768; 1:5000; RRID:AB_477523) were purchased from Sigma-Aldrich. Antibodies against GluA1 (catalog \#AB32436; 1:1000; RRID:AB_2113592), Rab3A (catalog \#ab3335; 1:700; RRID:AB_303714), PKA regulatory subunit II $\alpha$ (PKA RII $\alpha$; catalog \#ab38949; 1:1000; RRID:AB_725890), PKA RII $\beta$ (catalog \#ab75993;
1:1000; RRID:AB_1524201), and PKA RI $\alpha$ (catalog \#ab38936; 1:500; RRID: AB_777492) were purchased from Abcam. Antibodies against PSD95 (catalog \#3450S; 1:1000; RRID:AB_2292883) and PKA catalytic subunit $\alpha$ (PKA C $\alpha$; catalog \#4782; 1:1500; RRID:AB_10698746) were purchased from Cell Signaling Technology. Antibody against AKAP79/ 150 (catalog \#sc-10765; 1:2000; RRID:AB_2289482) was purchased from Santa Cruz Biotechnology. Horseradish peroxidase (HRP)-linked goat anti-mouse IgG and goat anti-rabbit IgG for Western blot test were purchased from Millipore.

Brain slice preparations and electrophysiology. The anatomical terminology is based on the atlas of Franklin and Paxinos (1997). The rostrocaudal levels correspond to $1.5-0.5 \mathrm{~mm}$ insular cortex relative to the bregma. The mice were anesthetized with $2 \%$ isoflurane, and brain slices $(300 \mu \mathrm{m})$ containing the insular cortex were cut at $4^{\circ} \mathrm{C}$ with a vibratome in oxygenated ACSF containing (in mM): $124 \mathrm{NaCl}, 2 \mathrm{KCl}, 26 \mathrm{NaHCO}_{3}$, $2 \mathrm{CaCl}_{2}, 2 \mathrm{MgSO}_{4}, 1 \mathrm{NaH}_{2} \mathrm{PO}_{4}$, and 10 D-glucose, $\mathrm{pH}$ 7.4. For electrophysiology, brain slices were transferred to a submerged recovery chamber with oxygenated ACSF at room temperature. Experiments were performed in a recording chamber on the stage of a BX51W1 microscope (Olympus) equipped with infrared differential interference contrast optics for visualizing whole-cell patch-clamp recordings. EPSCs were recorded from layer II and layer III neurons with an Axon 700B amplifier (Molecular Devices), and local stimulations were delivered with a bipolar tungsten stimulating electrode placed in layer $\mathrm{V}$ of the insular cortex. The recording pipettes $(2-5 \mathrm{M} \Omega$ ) were filled with a solution containing the following (in mM): $145 \mathrm{~K}$-gluconate, $5 \mathrm{NaCl}, 1 \mathrm{MgCl}_{2}, 0.2 \mathrm{EGTA}, 10$ HEPES, $2 \mathrm{Mg}$-ATP, $0.1 \mathrm{Na}_{3}$-GTP, and 10 phosphocreatine disodium, $\mathrm{pH}$ 7.2. AMPAR-mediated EPSCs were induced by repetitive stimulations at $0.05 \mathrm{~Hz}$, and neurons were voltage clamped at $-70 \mathrm{mV}$ in the presence of 2-amino-5-phosphonovaleric acid $(50 \mu \mathrm{M})$. For miniature EPSC (mEPSC) recording, $0.5 \mu \mathrm{M}$ tetrodotoxin was added in the perfusion solution. All experiments were conducted in the presence of picrotoxin $(100 \mu \mathrm{M})$ to block $\mathrm{GABA}_{\mathrm{A}}$ receptor-mediated inhibitory synaptic currents. The access resistance of $15-30 \mathrm{M} \Omega$ was monitored throughout the experiment. Data were discarded if the access resistance changed by $15 \%$ during an experiment.

Tissue preparation, subcellular fractionation, and Western blot analysis. Subcellular fractionation was conducted on tissue from C57BL/6 mice or transgenic mice using an adapted protocol (Pacchioni et al., 2009; Milnerwood et al., 2010). The insular cortices were dissected on ice in cold ACSF and homogenized in $0.32 \mathrm{M}$ sucrose buffer $(10 \mathrm{~mm}$ sucrose and 10 mM HEPES, pH 7.4) containing a protease inhibitor cocktail and phosphatase inhibitor cocktails 2 and 3. Samples were centrifuged $(1000 \times g$, $10 \mathrm{~min}, 4^{\circ} \mathrm{C}$ ) to yield the nuclear enriched pellet and the $\mathrm{S} 1$ fraction. The S1 fraction was then centrifuged $\left(12,000 \times g, 20 \mathrm{~min}, 4^{\circ} \mathrm{C}\right)$ to obtain the pellet (P2; crude synaptosomal membranes) fraction. To further digest synaptosomes and yield an insoluble "PSD-enriched" membrane fraction and a "non-PSD enriched" membrane fraction, we resuspended the P2 synaptosomal pellet in 4 mM HEPES buffer ( 4 mм HEPES and $1 \mathrm{~mm}$ EDTA, pH 7.4) and again centrifuged $\left(12,000 \times g, 20 \mathrm{~min}, 4^{\circ} \mathrm{C}\right)$. Resuspension and centrifugation was repeated. The resulting pellet was resuspended with buffer A ( $20 \mathrm{~mm}$ HEPES, $100 \mathrm{~mm} \mathrm{NaCl}, 0.5 \%$ Triton X-100, $\mathrm{pH} 7.2)$ and rotated slowly $\left(15 \mathrm{~min}, 4^{\circ} \mathrm{C}\right)$, followed by centrifugation $\left(12,000 \times g, 20 \mathrm{~min}, 4^{\circ} \mathrm{C}\right)$. The supernatant (Triton X-100-soluble nonPSD fraction) containing non-PSD membranes were retained. The pellet was resuspended in buffer B [ $20 \mathrm{~mm}$ HEPES, $0.15 \mathrm{~mm} \mathrm{NaCl}, 1 \%$ Triton $\mathrm{X}-100,1 \%$ deoxycholic acid, $1 \%$ SDS, and $1 \mathrm{~mm}$ dithiothreitol (DTT), $\mathrm{pH} 7.5)$, followed by gentle rotating $\left(1 \mathrm{~h}, 4^{\circ} \mathrm{C}\right)$ and centrifugation $\left(10,000 \times g, 15 \mathrm{~min}, 4^{\circ} \mathrm{C}\right)$. The pellet was discarded, and the supernatant (Triton X-100-insoluble PSD fraction) was retained. PSD and non-PSD samples were stored at $-80^{\circ} \mathrm{C}$ until use. Western blotting was conducted as described previously (Wang et al., 2008). Protein concentration was normalized with the Bradford assay. Electrophoresis of equal amounts of total protein was performed on SDS-polyacrylamide gels. Separated proteins were transferred onto polyvinylidene membranes at $4^{\circ} \mathrm{C}$. The membranes were blocked [ $2 \mathrm{~h}$, room temperature, $5 \%$ milk or $5 \%$ bovine serum albumin (BSA) in TBST (Tris-buffered saline with Tween 20)] and incubated with primary antibody (5\% BSA in TBST, $4^{\circ} \mathrm{C}$ overnight). After being washed, the membranes were incubated with the appropriate 
A

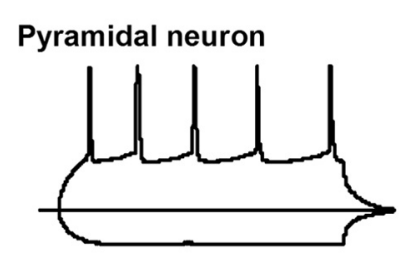

Interneuron

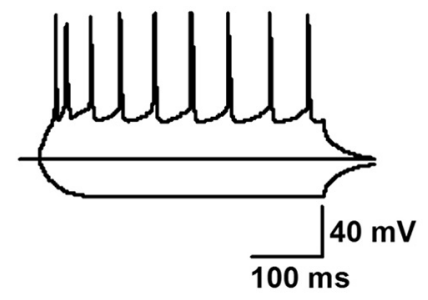

B
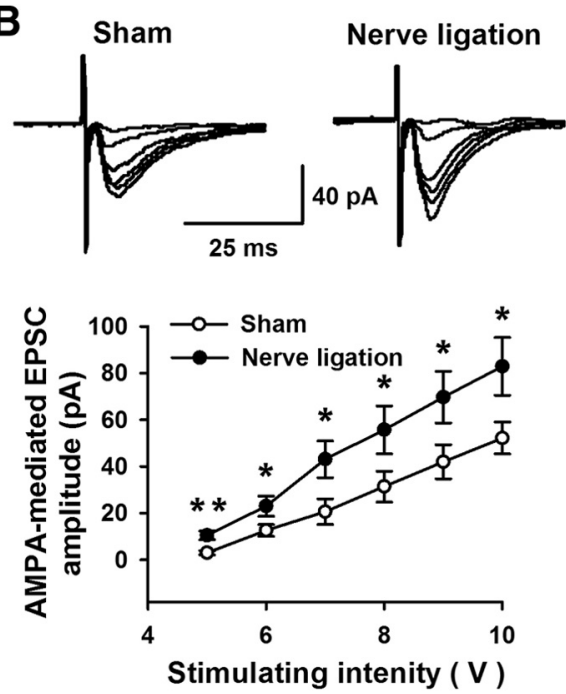

Figure 1. AMPAR-mediated synaptic transmission is enhanced in the insular cortex after nerve ligation. $A$, When injected with current steps from -100 to $100 \mathrm{pA}$ in $400 \mathrm{~ms}$, the pyramidal neuron fired repetitive action potentials with frequency adaptation (top). The interneurons showed the fast-spike properties (bottom). $\boldsymbol{B}$, Synaptic input-output curves in slices from sham $(n=6$ neurons) and nerve-ligated ( $n=7$ neurons) mice. ${ }^{*} p<0.05$ and ${ }^{* *} p<0.01$ compared with sham control (two-way ANOVA). Open circles, Neurons from sham mice; filled circles, neurons from mice with nerve ligation.

HRP-coupled secondary antibody diluted 1:3000 for $1 \mathrm{~h}$, followed by enhanced chemiluminescence detection of the proteins with Western lightning Chemiluminescence Reagent Plus according to the instructions of the manufacturer. To verify equal loading, we also probed the membranes with an antibody against actin or tubulin. The density of the immunoblots was measured with the NIH ImageJ program.

Coimmunoprecipitation. Coimmunoprecipitation was performed as reported previously with some modifications (Wang and Storm, 2003). Adult mouse insular cortex was homogenized in radioimmunoprecipitation assay buffer (50 mm Tris- $\mathrm{HCl}, 150 \mathrm{~mm} \mathrm{NaCl}, 1 \% \mathrm{NP}-40,1 \mathrm{~mm}$ EDTA, 1 mm DTT, and $0.5 \%$ sodium deoxycholate, $\mathrm{pH} 7.4$ ) containing a protease inhibitor cocktail. After centrifugation $(20,000 \times \mathrm{g}, 20 \mathrm{~min}$, $4^{\circ} \mathrm{C}$ ), the supernatant was preincubated with Protein A-agarose for $5 \mathrm{~h}$ at $4^{\circ} \mathrm{C}$ to preclear the preparation and then incubated with antibody against GluA1 or antibody against AKAP79/150 overnight at $4^{\circ} \mathrm{C}$. Protein A-agarose (GE Healthcare) was then added and incubated for another $2 \mathrm{~h}$ at $4^{\circ} \mathrm{C}$. The mixtures were washed four times, eluted by boiling in loading buffer, and subjected to Western blot.

Nociceptive behavioral experiments. Mice were placed in a round container and allowed to acclimate for $30 \mathrm{~min}$ before testing. Experiments were performed to characterize the threshold stimulus. Mechanical allodynia was assessed on the basis of the responsiveness of the hindpaw to the application of von Frey filaments (Stoelting) to the point of bending. Positive responses include licking, biting, and sudden withdrawal of the hindpaw. Mechanical allodynia was tested five times with an interval of $10 \mathrm{~min}$. To test for the tactile threshold required to evoke withdrawal of the stimulated paw, von Frey filaments with different bending forces $(0.008-0.04 \mathrm{~g})$ were applied to the middle of dorsum part of the hindpaw in an ascending order. Each filament was applied five times to its minimum bending force, and a paw-withdrawal threshold was defined as three positive responses. To avoid potential tissue damage, the cutoff threshold was assigned as $0.04 \mathrm{~g}$-force.

Cannula implantation and microinjection into the insular cortex. Mice were anesthetized by intraperitoneal injections of a mixture of $1.3 \mathrm{ml}$ of ketamine $(100 \mathrm{mg} / \mathrm{ml}$; Bimeda-MTC) and $0.5 \mathrm{ml}$ of xylazine $(20 \mathrm{mg} / \mathrm{ml}$; Bayer) in $8.2 \mathrm{ml}$ of normal saline at a dose of $10 \mu \mathrm{l} / \mathrm{g}$ body weight. Mouse heads were secured on a stereotaxic frame, and 24 gauge guide cannulae were implanted bilaterally into the insular cortex $(1.5 \mathrm{~mm}$ anterior to bregma, $\pm 3.5 \mathrm{~mm}$ lateral from the midline, $4.0 \mathrm{~mm}$ beneath the surface of the skull). The mice were given 1 week to recover after the cannula implantation. Intra-insular cortex injections were delivered via a 30 gauge injection cannula that was lowered $4.0 \mathrm{~mm}$ farther into the brain than the guide. The microinjection apparatus consisted of a Hamilton syringe $(10 \mu \mathrm{l})$ connected to an injector needle ( 30 gauge) by a thin polyethylene tube and a motorized syringe pump. CNQX $(1 \mathrm{~mm} / \mu \mathrm{l})$ was infused into each side of the insular cortex at a rate of $0.05 \mu \mathrm{l} /$ min; IEM $1460(1 \mathrm{~mm} / \mu \mathrm{l})$ was infused into unilateral or bilateral sides of the insular cortex at a similar rate of $0.05 \mu \mathrm{l} / \mathrm{min}$; an equivalent volume of saline was used as a control. After injection, the microinjection needle was left in place for at least $2 \mathrm{~min}$. The injection sites were confirmed at the end of all experiments, and sites outside of the insular cortex region were excluded from the study. The behavioral baseline responses were taken $1 \mathrm{~d}$ before the microinjection of the insular cortex. Mechanical threshold was then reassessed $30 \mathrm{~min}$ after the microinjection of either saline or CNQX or IEM 1460 in the insular cortex within 7-14 days after nerve injury.

Data analysis. Data are presented as the mean \pm SEM. Statistical analysis of differences between two groups was tested by unpaired, two-tailed Student's $t$ test or Mann-Whitney rank-sum test, based on normality test (Shapiro-Wilk) of the data. We used a two-way ANOVA and Tukey's test for post hoc test if there were two independent variables (for example, the input-output analysis in Fig. $1 B$ ). A probability value of $p<0.05$ was considered significant.

\section{Results}

Enhanced excitatory synaptic transmission in the insular cortex after nerve injury

We used an animal model of neuropathic pain as reported previously (Vadakkan et al., 2005; Xu et al., 2008; Qiu et al., 2013). Unilateral ligation of the CPN produced behavioral responses to non-noxious stimuli (or called mechanical allodynia) on day 3 after nerve ligation. Mechanical allodynia reached its peak on day 7 and lasted for at least 1 month. To explore whether there is any change in the basal excitatory synaptic transmission in the insular cortex during neuropathic pain, we recorded AMPAR-mediated EPSCs in pyramidal neurons in the layer II or layer III of acutely isolated insular cortical slices from nerve-ligated or sham mice on postsurgical day 7. Recorded neurons were identified as pyramidal neurons based on their ability to show spike frequency adaptation in response to prolonged depolarizing-current injection (Zhao et al., 2005; Fig. 1A). On postsurgical day 7, the slope of the input (stimulation intensity)-output (EPSC amplitude) curve was steeper after peripheral nerve ligation ( $n=7$ neurons) than that in the sham control ( $n=6$ neurons; Fig. $1 B$ ). This result suggests that the AMPAR-mediated excitatory synaptic transmission is increased in the insular cortex during neuropathic pain.

Next, we tested AMPAR-mediated mEPSCs in the insular cortex and found that the amplitude of mEPSCs was significantly increased in the nerve-ligated group than that in the sham control (sham, $18.5 \pm 0.6 \mathrm{pA}, n=13$ neurons; nerve ligation, $21.2 \pm 0.8$ pA, $n=19$ neurons; $p<0.05$; Fig. $2 A, B)$. Moreover, a greater increase in the frequency of mEPSC was observed on day 7 after nerve ligation than that in the sham control (sham, $0.5 \pm 0.02 \mathrm{~Hz}$, $n=11$ neurons; nerve ligation, $1.3 \pm 0.3 \mathrm{~Hz}, n=11$ neurons; $p<$ 0.05 ; Fig. $2 A, B)$. Paired-pulse facilitation (PPF) is a transient form of plasticity used commonly as a measure of presynaptic function, in which the response to the second stimulus is enhanced as a result of residual calcium in the presynaptic terminal 
A

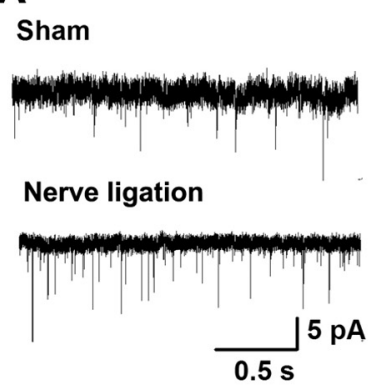

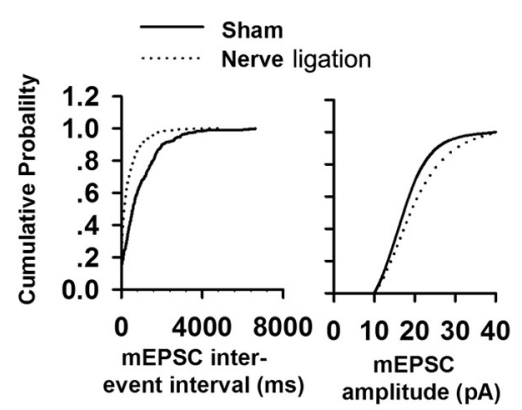

B

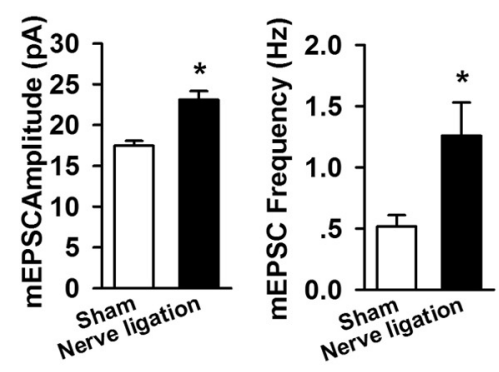

C

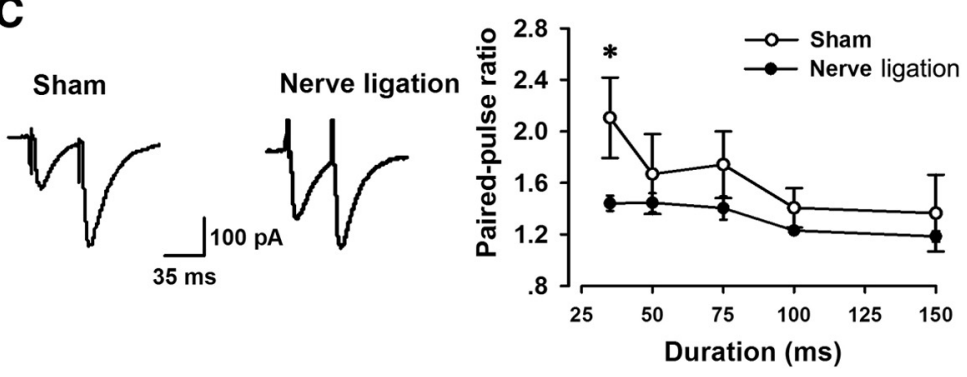

Figure 2. mEPSCs recorded in the insular cortex during neuropathic pain. $\boldsymbol{A}$, Representative mEPSCs recorded in the insular cortical neuron in slices from sham mice (top) and mice with nerve ligation (bottom) at a holding potential of $-70 \mathrm{mV}$. Cumulative interevent interval (left) and amplitude (right) histograms of mEPSC recorded in slices from sham mice (line) and mice with nerve ligation (dotted line). $\boldsymbol{B}$, Summary plots of mEPSC data. Averaged values of mEPSC parameters: mean amplitude (left, $n=13$ neurons for sham and $n=19$ neurons for nerve ligation) and mean peak frequency (right, $n=11$ neurons for both groups). C, Representative traces with an interval of $50 \mathrm{~ms}$ recorded in layer II/III of the insular cortex. Paired-pulse ratios (the ratio of EPSC2/EPSC 1 ) were recorded at intervals of 35, 50,75, 100, and 150 ms from sham and nerve-ligated mice. Open circles, Neurons from sham mice ( $n=6$ neurons); filled circles, neurons from mice with nerve ligation ( $n=11$ neurons). * $p<0.05$ compared with sham control (two-way ANOVA).

after the first stimulus (Foster and McNaughton, 1991). We found that PPF at a stimulus interval of $35 \mathrm{~ms}$ was significantly reduced in the insular neurons from nerve-ligated mice $(n=11$ neurons) compared with those from sham mice ( $n=6$ neurons; Fig. $2 C$ ). These findings indicate that peripheral nerve injury causes presynaptic enhancement of the excitatory synaptic transmission the insular cortex. Together, these results indicate that the enhanced excitatory synaptic transmission is attributable to an increase in the probability of presynaptic neurotransmitter release and an increase of postsynaptic responsiveness as well in the insular cortex after nerve ligation.

\section{Increased amount of synaptic GluA1 subunits in the insular cortex}

To assess whether postsynaptic AMPARs are involved in neuropathic pain, we performed biochemical analyses to investigate the abundance of AMPAR subunits in different subcellular fractions on days 3, 7, and 14 after surgery (Fig. 3A). The synaptosome was digested to yield an insoluble PSD-enriched (synaptic) membrane fraction and a soluble non-PSD enriched (peri/extrasynaptic and presynaptic) membrane fraction (Pacchioni et al., 2009; Milnerwood et al., 2010). A clear separation of PSD and non-PSD membranes was achieved as demonstrated by the distribution of PSD95, synaptophysin, and Rab3A (Fig. 3B). PSD95 sorted predominantly in the PSD fraction, whereas the marker of presynaptic membrane, synaptophysin, sorted primarily into the non-PSD fraction. Similarly, Rab3A, a presynaptically located neuronal GTP-binding protein, also associated primarily with the non-PSD fraction. AMPARs were located at both the extrasynaptic non-PSD fraction and the synaptic PSD fraction (Fig. $3 B)$. We found that the abundance of synaptic PSD GluA1 was significantly increased on postsurgical day $7(119 \pm 2 \%, p<0.01$, $n=7$ mice for each group; Fig. $3 C, E$ ) and postsurgical day 14
$(118 \pm 7 \%, p<0.05, n=4$ mice for each group; Fig. $3 D, E)$ but not on day 3 ( $n=4$ mice for each group; Fig. $3 D, E$ ). In contrast, no upregulation of synaptic PSD GluA2/3 was observed on postsurgical days 3,7 , or 14 ( $n=4-5$ mice for each group; Fig. $3 C-E)$. The abundance of extrasynaptic non-PSD GluA1 or GluA2/3 showed no changes at these three time points after nerve ligation ( $n=4-5$ mice for each group; Fig. $3 F, G)$. Together, these data indicate that the synaptic GluAl subunit is specifically increased in the insular cortex during neuropathic pain.

\section{Enhanced phosphorylation of synaptic GluA1 at the Ser845 site}

Phosphorylation of GluA1 regulates the localization and function of AMPARs ( $\mathrm{Lu}$ and Roche, 2012). To assess whether GluA1 phosphorylation is changed in the insular cortex during neuropathic pain, we focused on two serine phosphorylation sites of GluA1, Ser845, a PKA site, and Ser831, a CaMKII and PKC site. We found that the phosphorylation of synaptic GluA1 at the Ser845 site was significantly enhanced in the insular cortex on day 7 after nerve ligation compared with sham control (129 $\pm 10 \%, p$ $<0.05, n=5$ mice for each group; Fig. $4 A, C)$. In contrast, phosphorylation of extrasynaptic GluA1 at the Ser845 site was significantly decreased at the same time point $(80 \pm 4 \%, p<0.05$, $n=5$ mice for each group; Fig. $4 D, F)$. Phosphorylation of synaptic or extrasynaptic GluA1 at the Ser831 site was not changed on day 7 after nerve ligation (Fig. $4 B, C, E, F$ ). This indicates that the phosphorylation of synaptic GluAl is relatively site selective.

Requirement of phosphorylation of GluA1 at the Ser845 site To examine the role of phosphorylation in the upregulation of insular GluA1 during neuropathic pain, we used two lines of mutant mice specifically lacking phosphorylation of the Ser845 site (GluA1-S845A mutants) or lacking phosphorylation of the 
A
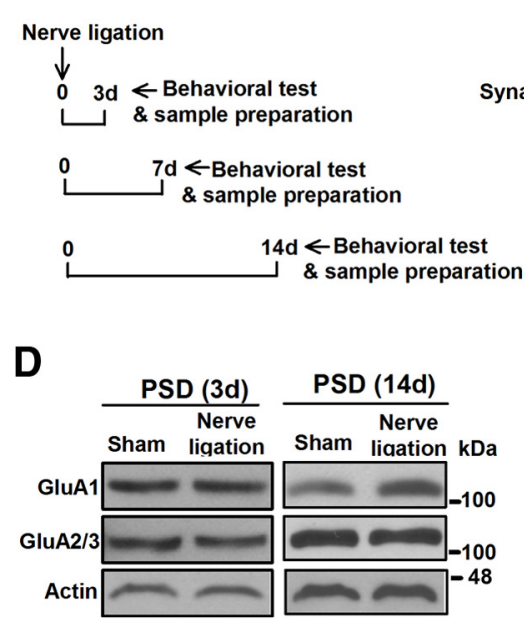

B

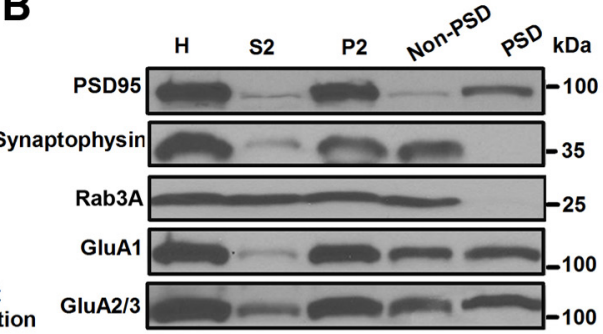

C

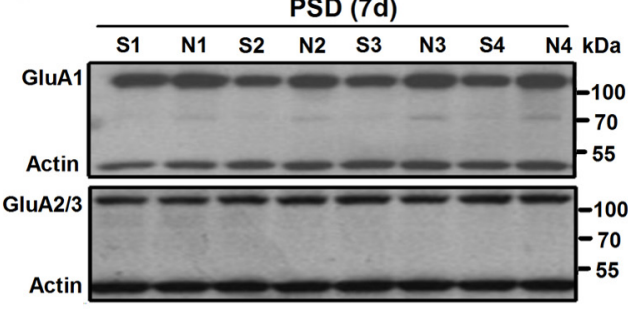

$\mathbf{E}$

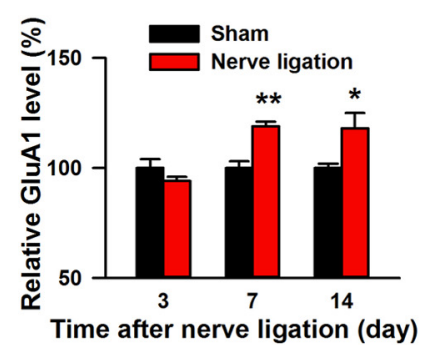

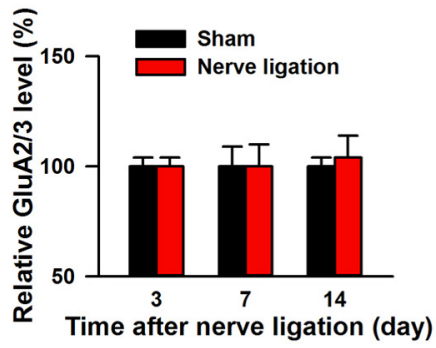

$\mathbf{F}$

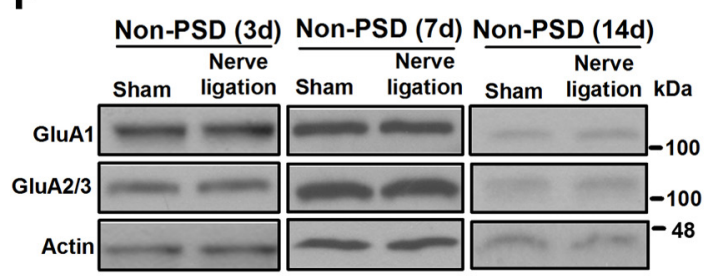

G

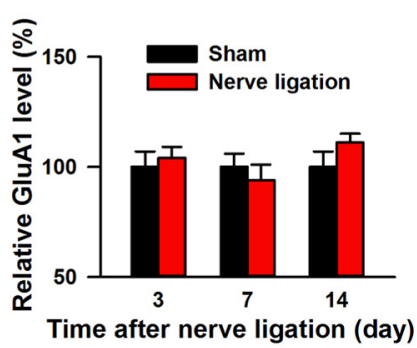

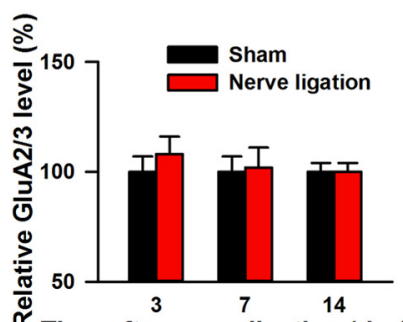

$\stackrel{\sim}{\Upsilon}$ Time after nerve ligation (day)

Figure 3. Synaptic GluA1, but not GluA2/3, is upregulated in the insular cortex during neuropathic pain. $\boldsymbol{A}$, The schematic diagram of the behavioral and biochemical experiments. $\boldsymbol{B}$, Fractionation of the insular cortex was probed for PSD95, synaptophysin, and Rab3A to confirm the accuracy of the subcellular fractionation procedure. H, Homogenate; $\mathrm{S2}$, cytosome; $\mathrm{P2}$, crude synaptosome; Non-PSD, non-PSD enriched fraction; PSD, PSD-enriched fraction. C, Representative Western blots for GluA1 and GluA2/3 in the PSD fraction of the insular cortex obtained on postsurgical day 7 . S, Sham; $N$, nerve ligation. $D$, Representative Western blots for GluA1 and GluA2/3 in the PSD fraction of the insular cortex obtained on postsurgical days 3 and 14. $\boldsymbol{E}$, The abundance of GluA1 in the PSD fraction was significantly increased on postsurgical days 7 and 14 but not on day $3(n=4-7$ mice for each group). The abundance of GluA2/3 in the PSD fraction showed no changes after nerve ligation ( $n=4-5$ mice for each group). $F$, Representative Western blots for GluA 1 and GluA2/3 in the non-PSD fraction of the insular cortex obtained on postsurgical days 3,7 , and 14. G, The abundance of GluA1 or GluA2/3 showed no change after nerve ligation $\left(n=4-5\right.$ mice for each group). ${ }^{*} p<0.05$, ${ }^{* *} p<$ 0.01 compared with sham control.

A

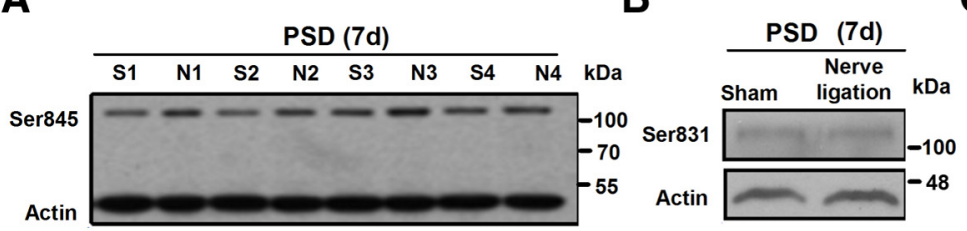

D

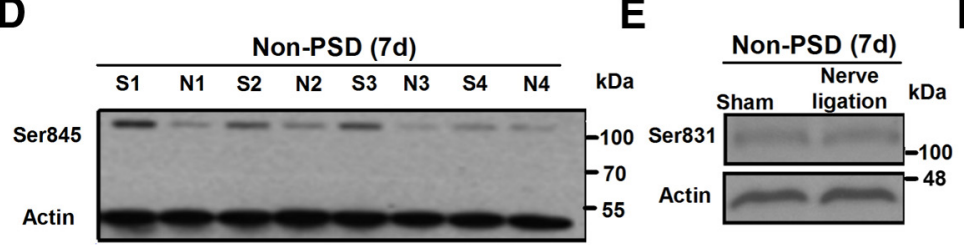

C $\bar{\Phi}$

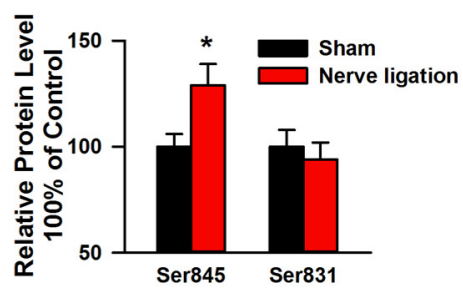

$\mathbf{F}$

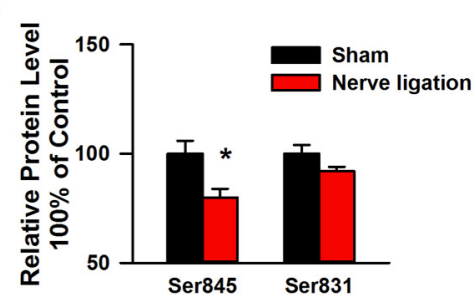

Figure 4. Phosphorylation of GluA1 at the Ser845 site is enhanced in the insular cortex after nerve ligation. $A$, Representative Western blots for phosphorylation of GluA1 at the Ser845 site in the PSD fraction on day 7 after nerve ligation. $\boldsymbol{B}$, Representative Western blots for phosphorylation of GluA1 at the Ser831 site in the PSD fraction on day 7 after nerve ligation. $\boldsymbol{C}$, In the PSD fraction, phosphorylation of GluA1 at the Ser845 site, but not at the Ser831 site, was significantly increased on day 7 after nerve ligation ( $n=5$ mice for each group). $\boldsymbol{D}$, Representative Western blots for phosphorylation of GluA1 at the Ser845 site in the non-PSD fraction on day 7 after nerve ligation. $\boldsymbol{E}$, Representative Western blots for phosphorylation of GluA1 at the Ser831 site in the PSD fraction on day 7 after nerve ligation. $\boldsymbol{F}$, In the non-PSD fraction, phosphorylation of GluA1 at the Ser845 site was significantly decreased on day 7 after nerve ligation ( $n=5$ mice for each group). Phosphorylation of GluA1 at the Ser831 site showed no change ( $n=5$ mice for each group). ${ }^{*} p<0.05$ compared with sham control. $\mathrm{S}$, Sham; $\mathrm{N}$, nerve ligation. 
A

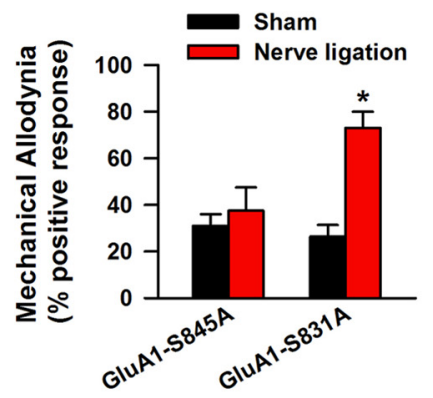

C
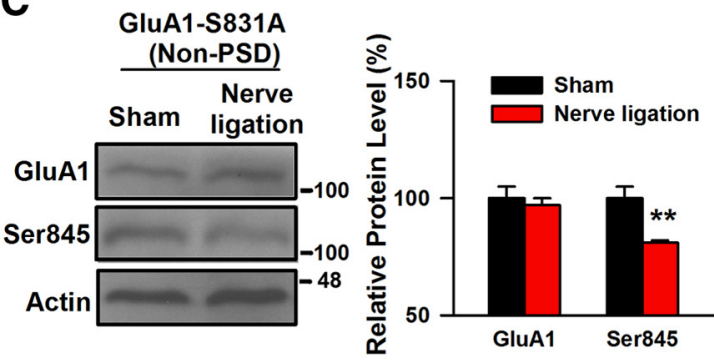

E

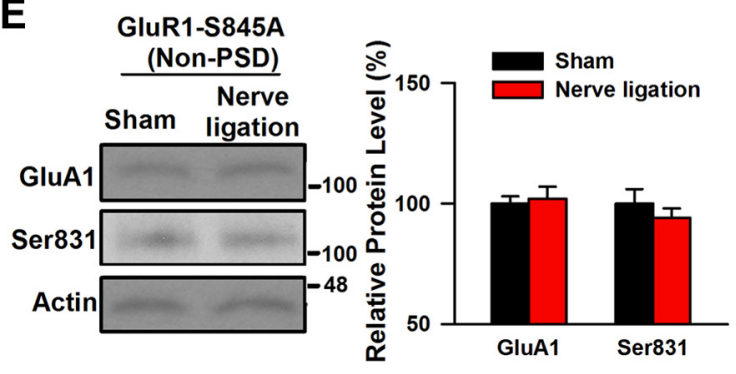

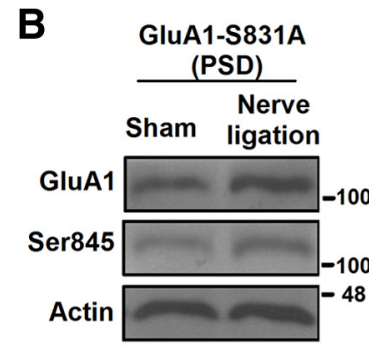

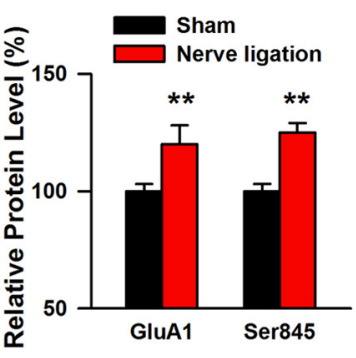

D

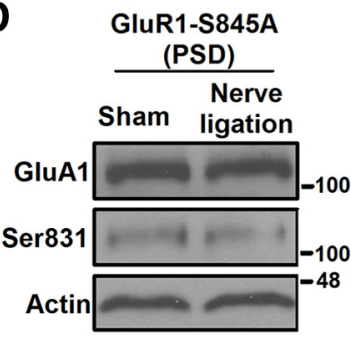

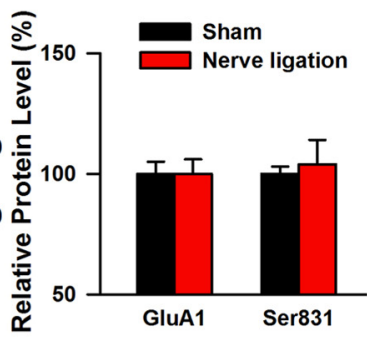

Figure 5. Phosphorylation of GluA1 at the Ser845 site is required for neuropathic pain-induced upregulation of GluA1. $A$, Mechanical allodynia was significantly increased in the GluA1-S831A mice with nerve ligation compared with sham control on postsurgical day 7 ( $n=5$ mice for each group) but not in the GluA1-S845A mice $\left(n=8\right.$ mice for each group). ${ }^{*} p<0.05$. $\boldsymbol{B}$, In the PSD fraction of the insular cortex from GluA1-S831A mice, the abundance of GluA1 and its phosphorylation at the Ser 845 site was significantly increased on day 7 after nerve ligation compared with sham control ( $n=5$ mice for each group). C, In the non-PSD fraction of the insular cortex from the GluA1-S831A mice, the phosphorylation of GluA1 at the Ser845 site was significantly reduced on day 7 after nerve ligation compared with sham control, whereas no change was observed for GluA1 ( $n=4$ mice for each group). $\boldsymbol{D}$, In the PSD fraction of the insular cortex from GluA1-S845A mice with nerve ligation, the abundance of GluA1 and its phosphorylation at the Ser 845 site showed no change compared with sham control ( $n=5$ mice for each group). $E$, No change was observed for $G$ luA 1 or its phosphorylation at the Ser845 site in the non-PSD fraction of the insular cortex from GluA1-S845A mice with nerve ligation compared with sham control ( $n=3$ mice for each group). ${ }^{* *} p<$ 0.01 compared with sham control.

Ser831 site (GluA1-S831A mutants; Clem and Huganir, 2010). We first evaluated the mechanical allodynia of these two lines after nerve ligation and found that the GluA1-S845A mice showed fewer responses to non-noxious mechanical stimulation on day 7 after nerve ligation compared with that of the sham group ( $p>0.05, n=8$ mice for each group; Fig. $5 A$ ), whereas the GluA1-S831A mice still demonstrated marked hypersensitization to non-noxious mechanical stimulation $(p<0.05, n=5$ mice for each group; Fig. $5 A$ ) after nerve ligation. It indicates that phosphorylation of GluA1 at the Ser845 site is important for behavioral sensitization during neuropathic pain.

Next, we examined the abundance of synaptic GluAl and its phosphorylation in the insular cortex of GluA1-S845A mice or GluA1-S831A mice during neuropathic pain. Synaptic GluA1 was significantly upregulated in GluA1-S831A mice on day 7 after nerve ligation compared with sham controls $(120 \pm 8 \%, p<$ $0.01, n=4$ mice for each group; Fig. $5 B$ ). In addition, phosphorylation of synaptic GluA1 at the Ser845 site was significantly increased ( $125 \pm 4 \%, p<0.01, n=5$ mice for each group; Fig. $5 B$ ). The abundance of extrasynaptic GluA1 in the insular cortex of GluA1-S831A mice showed no significant changes $(97 \pm 3 \%$, $n=4$ mice for each group; Fig. $5 C$ ), whereas phosphorylation of GluA1 at the Ser845 site was significantly decreased $(81 \pm 1 \%, p$ $<0.01, n=4$ mice for each group; Fig. $5 C$ ). It indicates that phosphorylation of the Ser831 site has no effect on the modification of synaptic GluA1 during neuropathic pain. However, in the insular cortex of GluA1-S845A mice, the abundance of synaptic or extrasynaptic GluA1 showed no change on day 7 after nerve ligation compared with sham control $(n=3-5$ mice for each group; Fig. $5 D, E$ ). In addition, no change was observed for phosphorylation of GluA1 at the Ser831 site $(n=3-5$ mice for each group; Fig. $5 D, E$ ). These results indicate that phosphorylation of GluA1 at the Ser845 site is required for the upregulation of synaptic GluA1.

\section{Recruitment of AKAP79/150 and PKA to the synapse in the} insular cortex

Phosphorylation of GluA1 at the Ser845 site is a substrate of PKA. AKAP79/150 is the main adaptor that combines PKA with GluA1 through PSD binding proteins, such as synapse-associated protein 97 (SAP97) or PSD95, and determines the localization of PKA (Sanderson and Dell'Acqua, 2011). Next, we decided to 
A

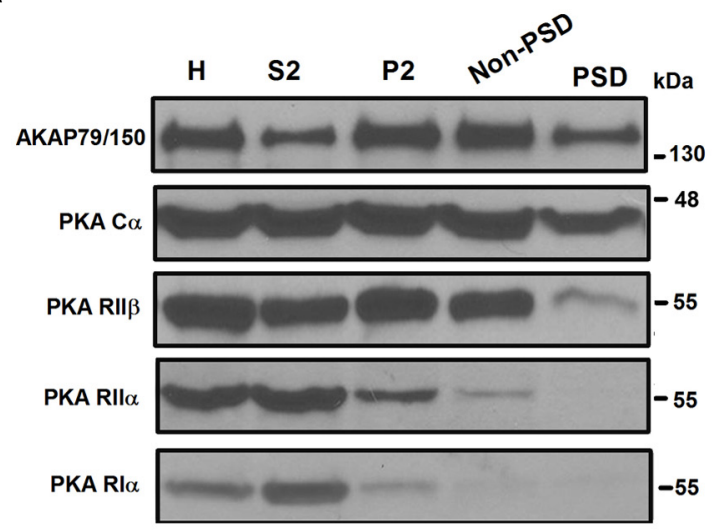

B

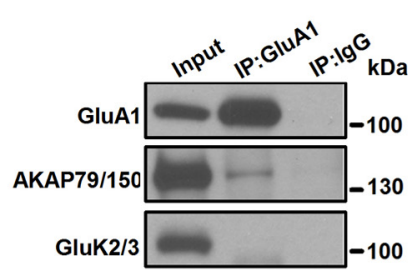

C

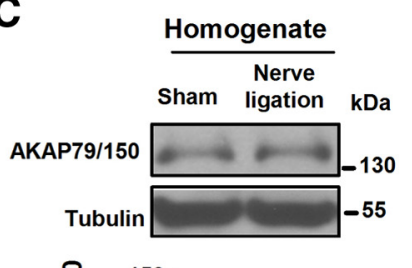

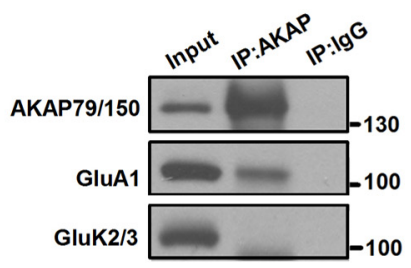

D

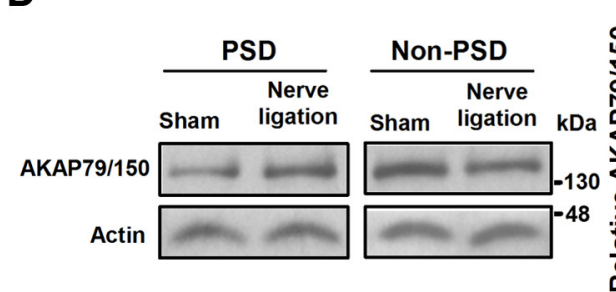

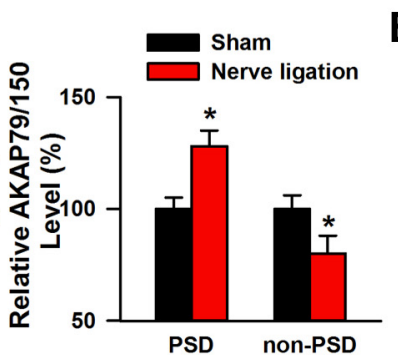

$\mathbf{E}$

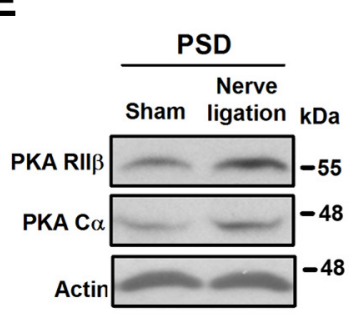

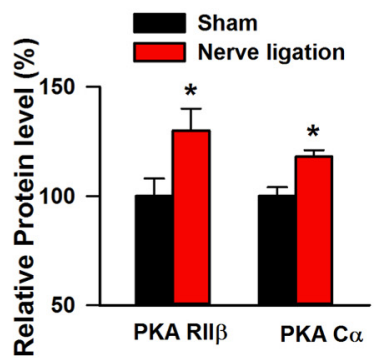

Figure 6. AKAP79/150 and PKA are recruited to the synapses during neuropathic pain. $\boldsymbol{A}$, Subcellular localization of AKAP79/150 and different PKA subunits in the insular cortex. $B$, Top, Extracts from the insular cortex were immunoprecipitated with antibody against GluA1 and blotted with antibodies against GluA1, AKAP79/150, and GluK2/3. GluA1 was coimmunoprecipitated with AKAP79/150 but not with GluK2/3. Bottom, Extracts from the insular cortex were immunoprecipitated with antibody against AKAP79/150 and blotted with antibodies against GluA1, AKAP79/150, and GluK2/3. AKAP79/150 was coimmunoprecipitated with GluA1 but not with GluK2/3 ( $n=3$ independent experiments). C, AKAP79/150 amount in the homogenate of the insular cortex showed no change on day 7 after nerve ligation compared with the sham group ( $n=5$ mice for each group). $\boldsymbol{D}$, AKAP79/150 amount was significantly increased in the PSD fraction ( $n=6$ mice for each group) but decreased in the non-PSD fraction of the insular cortex ( $n=5$ mice for each group) on day 7 after nerve ligation. $\boldsymbol{E}$, The abundance of PKA RII $\beta$ and PKA $C \alpha$ was significantly increased in the PSD fraction of the insular cortex on day 7 after nerve ligation ( $n=5$ mice for each group). ${ }^{*} p<0.05$ compared with the sham group. H, Homogenate; $S 2$, cytosome; $P 2$, crude synaptosome; Non-PSD, non-PSD enriched fraction; PSD, PSD-enriched fraction.

evaluate the localization of PKA and AKAP79/150 in the insular cortex during neuropathic pain. Using subcellular fractionation of the insular cortex, we found that AKAP79/150 was located at both the synaptic and extrasynaptic sites of the insular cortex (Fig. 6A). In addition, the antibody directed against GluA1 immunoprecipitated AKAP79/150 along with GluA1 but not GluK2/3 (Fig. 6B). Likewise, the antibody directed against AKAP79/150 immunoprecipitated GluA1 along with AKAP79/ 150 but not GluK2/3 (Fig. 6B), indicating that AKAP79/150 is present together within AMPAR complexes in the insular cortex. We tested the total expression level of AKAP79/150 on day 7 after nerve ligation and found that there was no significant difference between the sham group and the nerve ligation group $(n=5$ mice for each group; Fig. 6C). However, the abundance of AKAP79/ 150 in the PSD fraction was significantly increased $(128 \pm 7 \%, p$ $<0.05, n=6$ mice for each group), whereas that of AKAP79/150 in the non-PSD fraction was significantly decreased $(80 \pm 8 \%, p$ $<0.05, n=5$ mice for each group; Fig. $6 D$ ). These results indicate that, in the insular cortex, AKAP79/150 is translocated from the extrasynaptic site to the synaptic site during neuropathic pain.

PKA is a tetramer formed by two catalytic subunits (C) and two regulatory subunits (R) (Ventra et al., 1996; Brandon et al., 1997). We performed the biochemical analysis to determine their subcellular distribution in the insular cortex. We found that PKA RII $\alpha$ and PKA RI $\alpha$ were preferentially located in the cytosolic fraction but not the synaptosome of the insular cortex. In addition, neither PKA RII $\alpha$ nor PKA RI $\alpha$ was observed in the PSD fraction (Fig. 6A). In contrast, both PKA C $\alpha$ and PKA RII $\beta$ were found in the PSD fraction (Fig. 6A), suggesting that PKA C $\alpha$ and PKA RII $\beta$ were the dominantly expressed subunits in the synapse of the insular cortex. Next, we focused on the abundance of PKA $\mathrm{C} \alpha$ and PKA RII $\beta$. On day 7 after nerve ligation, both PKA C $\alpha$ subunit (118 $\pm 3 \%, p<0.05, n=5$ mice for each group) and PKA RII $\beta$ subunit $(130 \pm 10 \%, p<0.05, n=5$ mice for each group) were significantly enhanced in the PSD fraction (Fig. 6E). Together with our data that the phosphorylation level of synaptic GluA1 at the Ser845 site was increased during neuropathic pain, these results suggest that, in the insular cortex, the activity of PKA in the synaptic site may be enhanced after nerve ligation.

\section{Requirement of AC1 in the enhancement of synaptic GluA1}

$\mathrm{ACl}$ is the major $\mathrm{Ca}^{2+} /$ calmodulin-stimulated $\mathrm{AC}$ isoform among the cAMP signaling pathway (Cooper et al., 1998; Cooper and Crossthwaite, 2006). To explore the role of AC1 in the regulation of AMPAR in the insular cortex, we used the knock-out mice lacking AC1 ( $\mathrm{ACl}^{-1-}$ mice). We found that the amount of synaptic GluA1 and its phosphorylation at the Ser845 site remained unchanged in the insular cortex on day 7 after nerve ligation compared with sham control $(99 \pm 5 \%$ for GluA1 and $96 \pm 7 \%$ for GluA1-Ser 845 , respectively, $p>0.05, n=4$ mice for each group; Fig. 7A). Furthermore, no upregulation of AKAP79/ 150 , PKA C $\alpha$, or PKA RII $\beta$ was detected from the $A C 1^{-/-}$mice with nerve ligation compared with sham controls $(105 \pm 9 \%$ for AKAP79/150, $90 \pm 6 \%$ for PKA RII $\beta$, and $98 \pm 2 \%$ for PKA C $\alpha$, 
respectively, $p>0.05, n=5$ mice for each group; Fig. $7 B$ ). Moreover, in the nonPSD fraction of the insular cortex from the $A C 1^{-1-}$ mice, no decrease in the abundance of AKAP79/150 or phosphorylation of GluA1 at the Ser845 site was observed $(103 \pm 11 \%$ for AKAP79/150 and $99 \pm 4 \%$ for GluA1-Ser845, respectively, $p>0.05, n=5-6$ mice for each group; Fig. 7C). Together, these results indicate that AC1 is essential for the translocation of AKAP79/150 and PKA to the synaptic site and then for the enhancement of synaptic GluA1 in the insular cortex.

Effects of inhibiting GluA1-containing AMPARs in the insular cortex on behavioral sensitization

Our biochemical results showed that function and synaptic localization of GluA1-containing AMPARs were upregulated in the insular cortex after nerve ligation. To test whether insular GluA1containing AMPARs may contribute to nerve ligation-induced behavioral sensitization, we first microinjected the AMPAR/ kainate receptor antagonist CNQX into the insular cortex and evaluated the effect of CNQX on the pain threshold of the injured hindpaw and contralateral feet (Fig. 8A). After bilateral microinjection of CNQX $(0.5 \mu \mathrm{l} /$ side; $1 \mathrm{~mm} / \mu \mathrm{l})$ into the insular cortex on postsurgical day 7 , behavioral sensitization of both the injured and the contralateral hindpaws were significantly reversed as measured by the hindpaw-withdrawal thresholds ( $p$ values $<0.05, n=6$ mice for the CNQX group; Fig. $8 A, B)$. In contrast, microinjection of saline into the insular cortex bilaterally ( $n=4$ mice) did not have any significant effect ( $p$ values $>0.05$; Fig. $8 A, B$ ). Second, we microinjected the GluA1-containing AMPAR antagonist IEM $1460(0.5 \mu \mathrm{l} /$ side; $1 \mathrm{~mm} / \mu \mathrm{l})$ into the insular cortex and assessed the effect of IEM 1460 on the mechanical allodynia induced by nerve ligation. After unilateral or bilateral microinjection of IEM 1460 into the insular cortex on postsurgical days 8-14, both ipsilateral and contralateral mechanical allodynia were decreased compared with those of the saline groups ( $p$ values $<0.05, n=7$ mice for the unilateral IEM 1460 group, $n=6$ for the saline group, $n=6$ for the bilateral IEM 1460 group, $n=5$ for the saline group; Fig. $8 C, D)$. In contrast, there was no difference in bilateral mechanical responses after bilateral microinjection of IEM 1460 and saline in the sham groups ( $p$ values $>0.05, n=5$ for the IEM 1460 group, $n=5$ for the saline group; Fig. $8 E$ ).

\section{Discussion}

In this study, we provide strong evidence that AMPAR-mediated excitatory synaptic transmission is enhanced and synaptic GluA1 is upregulated in the insular cortex of adult mice during neuropathic pain. Blocking insular GluAl-containing AMPARs reduced nerve injury-induced mechanical allodynia. These results indicate that insular AMPARs undergo long-term enhancement after nerve injury, and this enhancement is critical for behavioral sensitization after nerve injury. Furthermore, we reveal that phosphorylation of synaptic GluA1 AMPARs at the Ser845 site determines the increase of the synaptic GluA1 subunit. Activation of calcium-stimulated AC1 and then translocation of AKAP79/150 and PKA to the synapse may contribute to the maintenance of the enhanced phosphorylation status of synaptic GluA1 AMPARs in the insular cortex.

\section{Insular cortex and neuropathic pain}

The insular cortex is critical in pain and sensory perception (Ostrowsky et al., 2002; Mazzola et al., 2009, 2012). Several lines of evidence suggest the enhanced activation of the insular cortex in experimental animals and in patients of neuropathic pain (Garcia-Larrea and Peyron, 2013). Inhibition or lesion of the insular cortex induces analgesia (Greenspan and Winfield, 1992; Burkey et al., 1999; Jasmin et al., 2003). However, little is known about whether excitatory transmission in the insular cortex undergoes plastic changes after peripheral nerve injury. Our previ- 
A

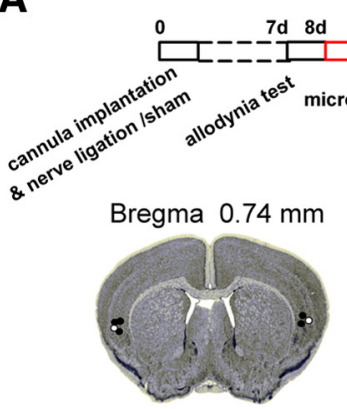

B
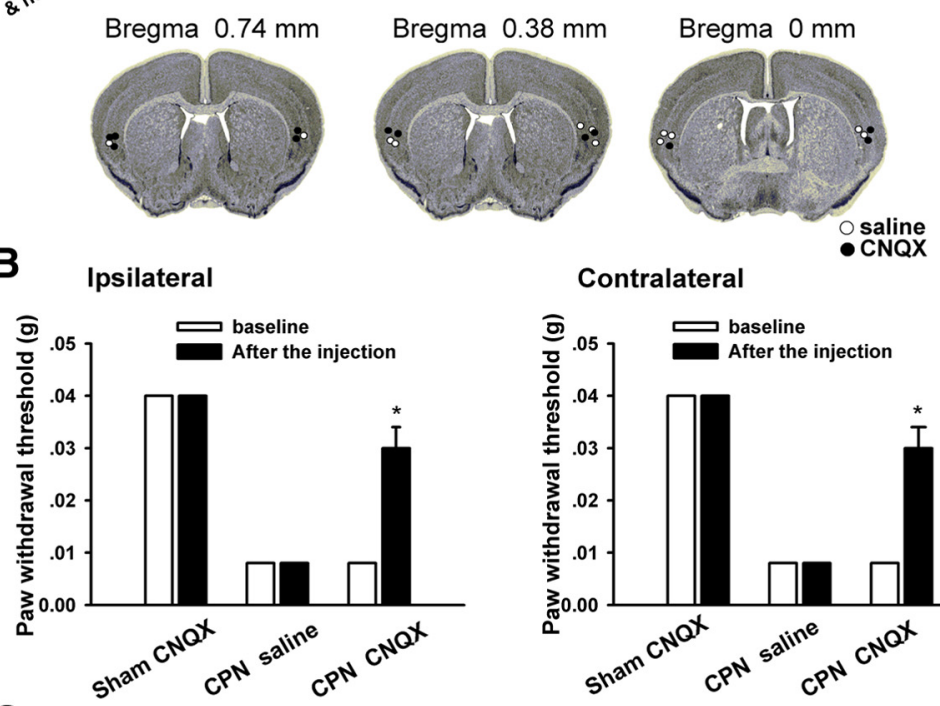

Contralateral

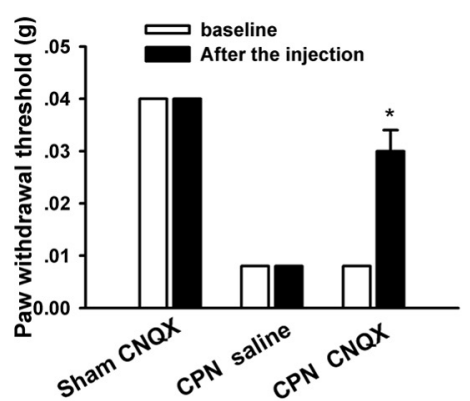

C Ipsilateral
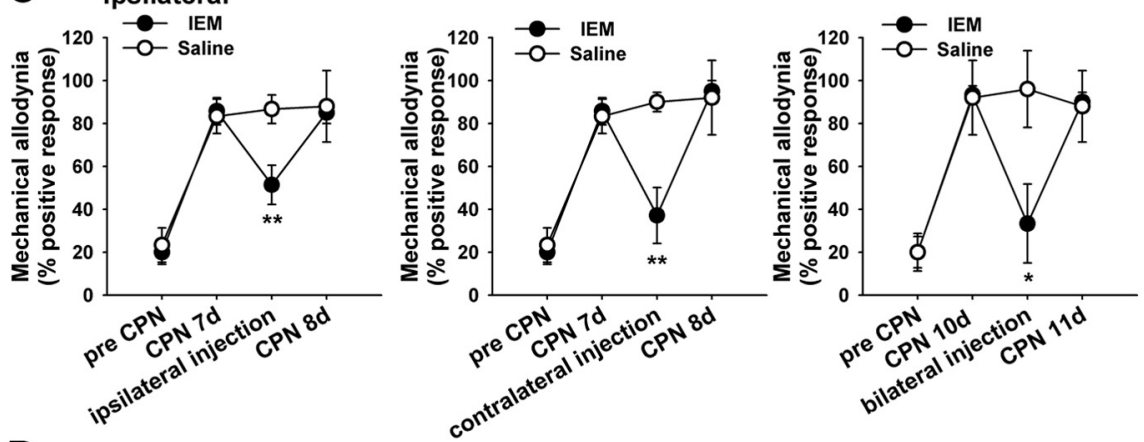

D Contralateral
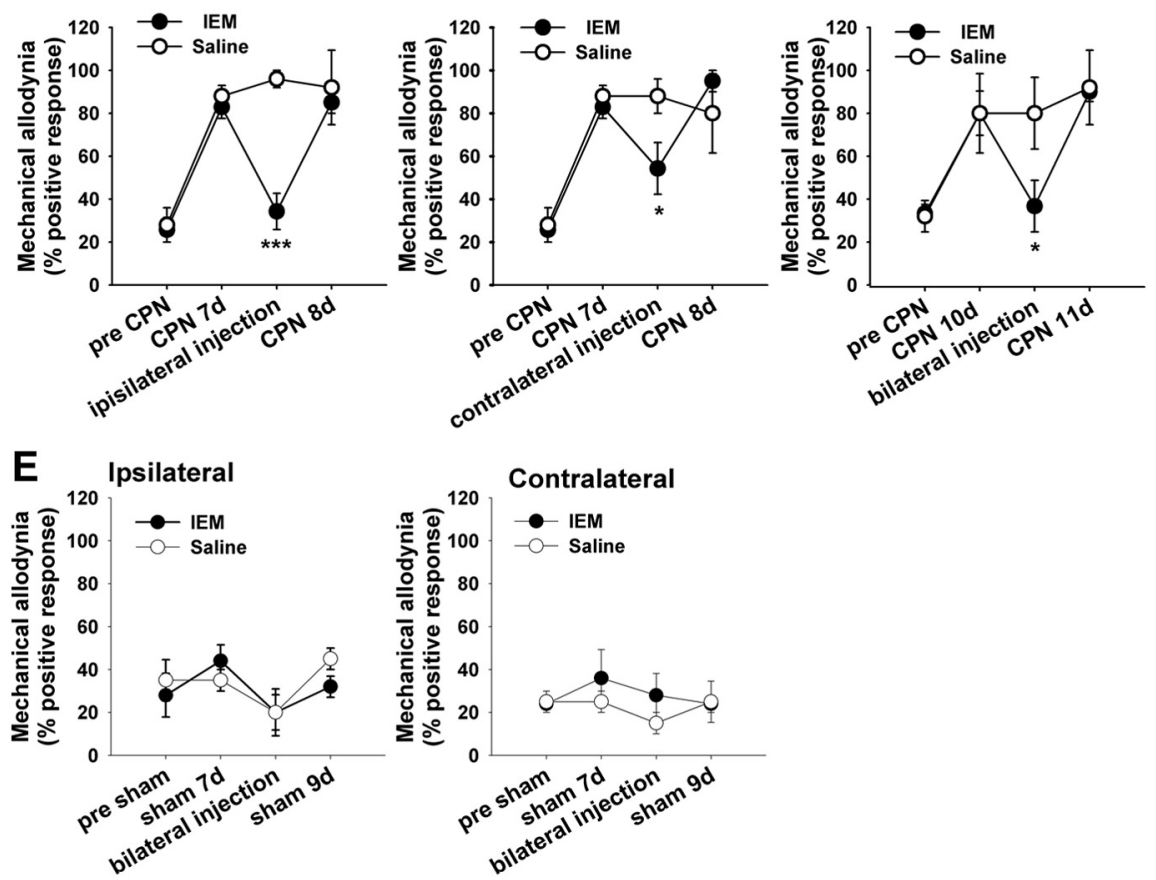

ous work has shown that AMPARs mediate most of the basal excitatory synaptic transmission in the insular cortex (Koga et al., 2012). In the present study, we found that the AMPAR-mediated synaptic transmission was increased in the insular cortex after nerve ligation. These results provide the first evidence that the excitatory transmission in the insular cortex was enhanced after peripheral nerve injury. More importantly, in recent work, we have found that upregulation of the insular NMDARs contributes to the development of neuropathic pain, and NMDAR-dependent LTP is occluded after neuropathic pain (Qiu et al., 2013). These results indicate that neuropathic pain may activate similar cortical signaling mechanisms that are also involved in electrically induced LTP in the insular cortex.

Furthermore, we found that synaptic GluA1, but not GluA2/3, was unregulated in the insular cortex during neuropathic pain, which indicated that increased calciumpermeable AMPARs (Cp-AMPARs) were formed in the insular cortex after nerve injury. Similarly, enhanced Cp-AMPARs are found in the spinal cord (Hartmann et al., 2004; Luo et al., 2008; Park et al., 2008) and the ACC (Xu et al., 2008) after peripheral injuries. These data indicate that the insular cortex, as one part of the CNS, may function in coordination with other brain regions (such as the ACC) by sharing the similar signaling mechanisms of the upregulation and phosphorylation of synaptic

Figure 8. Behavioral sensitization of insular GluA1-containing AMPARs.A, A schematic diagram of microinjection and the behavioral experiment and representative coronal section (top) showing injection sites in the insular cortex. The lower column shows the cannula tip placements in mice injected with CNQX or saline in the insular cortex. Scale bar, $1 \mathrm{~mm}$. B, After bilateral microinjection of CNQX $(1 \mathrm{~mm} / \mu \mathrm{l})$ into the insular cortex on day 7 after nerve injury, the pain thresholds of the injured hindpaw and contralateral feet were significantly increased (CNQX group, $n=6$ mice) compared with the saline-injected group (saline group, $n=4$ mice). C, After unilateral and bilateral microinjection of IEM 1460, ipsilateral mechanical allodynia were significantly decreased compared with the saline injection group (unilateral IEM 1460 group, $n=7$ mice; saline group, $n=6$ mice; bilateral IEM 1460 group, $n=6$ mice; saline group, $n=$ 5 mice). $\boldsymbol{D}$, After unilateral and bilateral microinjection of IEM 1460, contralateral mechanical allodynia were significantly decreased compared with the saline injection group (unilateral IEM 1460 group, $n=7$ mice; saline group, $n=6$ mice; bilateral IEM 1460 group, $n=6$ mice; saline group, $n=5$ mice). $\boldsymbol{E}$, There were no significant differences in bilateral mechanical allodynia after bilateral microinjection of IEM 1460 and saline in the sham group ( $P$ values $>0.05$, IEM 1460 group, $n=5$; saline group, $n=5)$. ${ }^{*} p<0.05,{ }^{* *} p<0.01$, ${ }^{* * *} p<0.001$ compared with the saline-injected group. 
GluA1-containing AMPARs. However, pharmacological inhibition of AMPAR-mediated synaptic transmission in the insular cortex or in the ACC can both reduce behavioral sensitization in neuropathic pain states, indicating that the insular cortex and the ACC of brain cortical areas can act independently in the modulation of neuropathic pain.

Previous work has shown that unilateral inhibition of the rostral agranular insular cortex produces a bilateral increase in withdrawal latency through a disinhibition of the descending inhibitory system (Jasmin et al., 2003). Similarly, we observed that either unilateral or bilateral microinjection of the AMPAR GluA1 antagonist IEM 1460 decreased bilateral mechanical allodynia after nerve injury. These results indicate that the insular cortex may exert bilaterally descending modulation on pain thresholds during neuropathic pain, in addition to its centrally bilateral process of painful information. Postsynaptic amplification of GluA1-containing AMPARs in the insular cortex may contribute to mechanical allodynia after nerve injury.

\section{AMPAR phosphorylation and chronic pain}

AMPARs are dynamically moving in and out of synapse based on synaptic activity, which in turn determines the synaptic strength and excitability (Gerges et al., 2006; Ehlers et al., 2007). Phosphorylation of AMPAR subunits is a major modification that regulates the synaptic localization of AMPARs. In this study, we found that phosphorylation of GluA1 at the Ser845 site in the insular cortex, but not at the Ser831 site, was required for behavioral sensitization. Enhanced phosphorylation of GluA1 at the Ser845 site has been reported in the ACC and spinal cord in chronic pain (Xu et al., 2008; Lee et al., 2012). These results emphasize the importance of the phosphorylation of GluAl in controlling AMPAR trafficking under pathological conditions. By using transgenic knock-in mice, we demonstrate that the GluA1-S845 site plays an important role in injury-induced behavioral sensitization. However, it is unlikely that behavioral effects are simply attributable to the upregulation of insular GluA1. Future studies are clearly needed to show the role of insular GluA1-S845A in behavioral sensitization by using regional selective mutant mice or alternative knock-out mice. From the signaling pathway point of view, phosphorylation of GluA1 at the Ser845 site attributable to the activation of AC1 and PKA may enhance synaptic AMPARs through inhibiting endocytosis of AMPARs (Kam et al., 2010) or increasing exocytosis of GluA1 to extrasynaptic sites on the plasma membrane and priming AMPARs for synaptic delivery (Oh et al., 2006). More work is needed to determine the molecular mechanism underlying the maintenance of enhanced GluA1 phosphorylation in the insular cortex after nerve injury.

\section{AC1-linked intracellular signaling pathways}

Phosphorylation of GluA1 at the Ser845 site is a substrate of PKA (Man et al., 2007; He et al., 2009). Synaptic localization of PKA and interaction of PKA with GluA1 are mediated mainly by AKAP79/150, an adaptor that may directly interact with PSDbinding proteins, such as SAP97 or PSD95, and then combines PKA with GluA1 together. In this study, we found that AKAP79/ 150 was translocated to the postsynaptic site of the insular cortex after nerve ligation, together with the RII $\beta$ and $C \alpha$ subunits of PKA after the activation of AC1. It indicates that the translocation of AKAP79/150 may lead to the enhanced activity of PKA and then increased phosphorylation of GluA1 at the Ser845 site. In line with our results, some research has found that AKAPs are not static anchors that position signaling proteins near fixed-target substrates and instead that AKAPs can regulate local signaling events in more dynamic manners (Dell'Acqua et al., 2006; Sanderson and Dell'Acqua, 2011). Moreover, a recent study reports that AKAP79/150 may be recruited to the postsynaptic part or recycling endosome by seizure activity in vivo and plasticityinducing stimuli in cultured hippocampal neurons (Keith et al., 2012). PKA is also found to be dynamically trafficked in the neuron (Zhong et al., 2009). These findings emphasize the emerging importance of translocation of AKAP79/150 and PKA in controlling synaptic function. AKAP79/150 anchors not only kinases but also phosphatases (such as calcineurin) in an appropriate synaptic position (Jurado et al., 2010; Kam et al., 2010; Dacher et al., 2013). Therefore, additional studies are clearly needed to find out how the balance between kinases and phosphatases are affected in chronic pain conditions.

\section{References}

Brandon EP, Idzerda RL, McKnight GS (1997) PKA isoforms, neural pathways, and behaviour: making the connection. Curr Opin Neurobiol 7:397-403. CrossRef Medline

Brooks JC, Zambreanu L, Godinez A, Craig AD, Tracey I (2005) Somatotopic organisation of the human insula to painful heat studied with high resolution functional imaging. Neuroimage 27:201-209. CrossRef Medline

Burkey AR, Carstens E, Jasmin L (1999) Dopamine reuptake inhibition in the rostral agranular insular cortex produces antinociception. J Neurosci 19:4169-4179. Medline

Clem RL, Huganir RL (2010) Calcium-permeable AMPA receptor dynamics mediate fear memory erasure. Science 330:1108-1112. CrossRef Medline

Cooper DM, Crossthwaite AJ (2006) Higher-order organization and regulation of adenylyl cyclases. Trends Pharmacol Sci 27:426-431. CrossRef Medline

Cooper DM, Karpen JW, Fagan KA, Mons NE (1998) Ca(2+)-sensitive adenylyl cyclases. Adv Second Messenger Phosphoprotein Res 32:23-51. Medline

Dacher M, Gouty S, Dash S, Cox BM, Nugent FS (2013) A-kinase anchoring protein-calcineurin signaling in long-term depression of GABAergic synapses. J Neurosci 33:2650-2660. CrossRef Medline

Dell'Acqua ML, Smith KE, Gorski JA, Horne EA, Gibson ES, Gomez LL (2006) Regulation of neuronal PKA signaling through AKAP targeting dynamics. Eur J Cell Biol 85:627-633. CrossRef Medline

Ehlers MD, Heine M, Groc L, Lee MC, Choquet D (2007) Diffusional trapping of GluR1 AMPA receptors by input-specific synaptic activity. Neuron 54:447-460. CrossRef Medline

Foster TC, McNaughton BL (1991) Long-term enhancement of CA1 synaptic transmission is due to increased quantal size, not quantal content. Hippocampus 1:79-91. CrossRef Medline

Franklin KBJ, Paxinos G (1997) The mouse brain in stereotaxic coordinates. San Diego: Academic.

Galan A, Laird JM, Cervero F (2004) In vivo recruitment by painful stimuli of AMPA receptor subunits to the plasma membrane of spinal cord neurons. Pain 112:315-323. CrossRef Medline

Garcia-Larrea L, Peyron R (2013) Pain matrices and neuropathic pain matrices: a review. Pain 154 [Suppl 1]:S29-S43. CrossRef

Gerges NZ, Backos DS, Rupasinghe CN, Spaller MR, Esteban JA (2006) Dual role of the exocyst in AMPA receptor targeting and insertion into the postsynaptic membrane. EMBO J 25:1623-1634. CrossRef Medline

Greenspan JD, Winfield JA (1992) Reversible pain and tactile deficits associated with a cerebral tumor compressing the posterior insula and parietal operculum. Pain 50:29-39. CrossRef Medline

Harris RE, Sundgren PC, Craig AD, Kirshenbaum E, Sen A, Napadow V, Clauw DJ (2009) Elevated insular glutamate in fibromyalgia is associated with experimental pain. Arthritis Rheum 60:3146-3152. CrossRef Medline

Hartmann B, Ahmadi S, Heppenstall PA, Lewin GR, Schott C, Borchardt T, Seeburg PH, Zeilhofer HU, Sprengel R, Kuner R (2004) The AMPA receptor subunits GluR-A and GluR-B reciprocally modulate spinal synaptic plasticity and inflammatory pain. Neuron 44:637-650. CrossRef Medline

He K, Song L, Cummings LW, Goldman J, Huganir RL, Lee HK (2009) 
Stabilization of Ca2+-permeable AMPA receptors at perisynaptic sites by GluR1-S845 phosphorylation. Proc Natl Acad Sci U S A 106:2003320038. CrossRef Medline

Henderson LA, Gandevia SC, Macefield VG (2008) Gender differences in brain activity evoked by muscle and cutaneous pain: a retrospective study of single-trial fMRI data. Neuroimage 39:1867-1876. CrossRef Medline

Ikeda H, Stark J, Fischer H, Wagner M, Drdla R, Jäger T, Sandkühler J (2006) Synaptic amplifier of inflammatory pain in the spinal dorsal horn. Science 312:1659-1662. CrossRef Medline

Jasmin L, Rabkin SD, Granato A, Boudah A, Ohara PT (2003) Analgesia and hyperalgesia from GABA-mediated modulation of the cerebral cortex. Nature 424:316-320. CrossRef Medline

Jurado S, Biou V, Malenka RC (2010) A calcineurin/AKAP complex is required for NMDA receptor-dependent long-term depression. Nat Neurosci 13:1053-1055. CrossRef Medline

Kam AY, Liao D, Loh HH, Law PY (2010) Morphine induces AMPA receptor internalization in primary hippocampal neurons via calcineurin-dependent dephosphorylation of GluR1 subunits. J Neurosci 30:15304-15316. CrossRef Medline

Keith DJ, Sanderson JL, Gibson ES, Woolfrey KM, Robertson HR, Olszewski K, Kang R, El-Husseini A, Dell'acqua ML (2012) Palmitoylation of A-kinase anchoring protein 79/150 regulates dendritic endosomal targeting and synaptic plasticity mechanisms. J Neurosci 32:7119-7136. CrossRef Medline

Koga K, Sim SE, Chen T, Wu LJ, Kaang BK, Zhuo M (2012) Kainate receptor-mediated synaptic transmissions in the adult rodent insular cortex. J Neurophysiol 108:1988-1998. CrossRef Medline

Kopach O, Kao SC, Petralia RS, Belan P, Tao YX, Voitenko N (2011) Inflammation alters trafficking of extrasynaptic AMPA receptors in tonically firing lamina II neurons of the rat spinal dorsal horn. Pain 152:912-923. CrossRef Medline

Larsson M, Broman J (2008) Translocation of GluR1-containing AMPA receptors to a spinal nociceptive synapse during acute noxious stimulation. J Neurosci 28:7084-7090. CrossRef Medline

Lee DZ, Chung JM, Chung K, Kang MG (2012) Reactive oxygen species (ROS) modulate AMPA receptor phosphorylation and cell-surface localization in concert with pain-related behavior. Pain 153:1905-1915. CrossRef Medline

Li J, Wu M, Zhuo M, Xu ZC (2013) Alteration of neuronal activity after digit amputation in rat anterior cingulate cortex. Int J Physiol Pathophysiol Pharmacol 5:43-51. Medline

Liu MG, Zhuo M (2014) Loss of long-term depression in the insular cortex after tail amputation in adult mice. Mol Pain 10:1. CrossRef Medline

$\mathrm{Lu} \mathrm{W}$, Roche KW (2012) Posttranslational regulation of AMPA receptor trafficking and function. Curr Opin Neurobiol 22:470-479. CrossRef Medline

Luo C, Seeburg PH, Sprengel R, Kuner R (2008) Activity-dependent potentiation of calcium signals in spinal sensory networks in inflammatory pain states. Pain 140:358-367. CrossRef Medline

Man HY, Sekine-Aizawa Y, Huganir RL (2007) Regulation of \{alpha\}amino-3-hydroxy-5-methyl-4-isoxazolepropionic acid receptor trafficking through PKA phosphorylation of the Glu receptor 1 subunit. Proc Natl Acad Sci U S A 104:3579-3584. CrossRef Medline

Mazzola L, Isnard J, Peyron R, Guénot M, Mauguière F (2009) Somatotopic organization of pain responses to direct electrical stimulation of the human insular cortex. Pain 146:99-104. CrossRef Medline

Mazzola L, Isnard J, Peyron R, Mauguière F (2012) Stimulation of the human cortex and the experience of pain: Wilder Penfield's observations revisited. Brain 135:631-640. CrossRef Medline

Milnerwood AJ, Gladding CM, Pouladi MA, Kaufman AM, Hines RM, Boyd JD, Ko RW, Vasuta OC, Graham RK, Hayden MR, Murphy TH, Raymond LA (2010) Early increase in extrasynaptic NMDA receptor signaling and expression contributes to phenotype onset in Huntington's disease mice. Neuron 65:178-190. CrossRef Medline

Oh MC, Derkach VA, Guire ES, Soderling TR (2006) Extrasynaptic membrane trafficking regulated by GluR1 serine 845 phosphorylation primes AMPA receptors for long-term potentiation. J Biol Chem 281:752-758. CrossRef Medline
Ostrowsky K, Magnin M, Ryvlin P, Isnard J, Guenot M, Mauguière F (2002) Representation of pain and somatic sensation in the human insula: a study of responses to direct electrical cortical stimulation. Cereb Cortex 12:376-385. CrossRef Medline

Pacchioni AM, Vallone J, Worley PF, Kalivas PW (2009) Neuronal pentraxins modulate cocaine-induced neuroadaptations. J Pharmacol Exp Ther 328:183-192. CrossRef Medline

Park JS, Yaster M, Guan X, Xu JT, Shih MH, Guan Y, Raja SN, Tao YX (2008) Role of spinal cord alpha-amino-3-hydroxy-5-methyl-4-isoxazolepropionic acid receptors in complete Freund's adjuvant-induced inflammatory pain. Mol Pain 4:67. CrossRef Medline

Qiu S, Chen T, Koga K, Guo YY, Xu H, Song Q, Wang JJ, Descalzi G, Kaang BK, Luo JH, Zhuo M, Zhao MG (2013) An increase in synaptic NMDA receptors in the insular cortex contributes to neuropathic pain. Sci Signal 6:ra34. CrossRef Medline

Sanderson JL, Dell'Acqua ML (2011) AKAP signaling complexes in regulation of excitatory synaptic plasticity. Neuroscientist 17:321-336. CrossRef Medline

Sandkühler J (2007) Understanding LTP in pain pathways. Mol Pain 3:9. CrossRef Medline

Shema R, Haramati S, Ron S, Hazvi S, Chen A, Sacktor TC, Dudai Y (2011) Enhancement of consolidated long-term memory by overexpression of protein kinase Mzeta in the neocortex. Science 331:1207-1210. CrossRef Medline

Starr CJ, Sawaki L, Wittenberg GF, Burdette JH, Oshiro Y, Quevedo AS, Coghill RC (2009) Roles of the insular cortex in the modulation of pain: insights from brain lesions. J Neurosci 29:2684-2694. CrossRef Medline

Vadakkan KI, Jia YH, Zhuo M (2005) A behavioral model of neuropathic pain induced by ligation of the common peroneal nerve in mice. J Pain 6:747-756. CrossRef Medline

Ventra C, Porcellini A, Feliciello A, Gallo A, Paolillo M, Mele E, Avvedimento VE, Schettini G (1996) The differential response of protein kinase A to cyclic AMP in discrete brain areas correlates with the abundance of regulatory subunit II. J Neurochem 66:1752-1761. CrossRef Medline

Wang H, Storm DR (2003) Calmodulin-regulated adenylyl cyclases: crosstalk and plasticity in the central nervous system. Mol Pharmacol 63:463468. CrossRef Medline

Wang H, Wu LJ, Zhang F, Zhuo M (2008) Roles of calcium-stimulated adenylyl cyclase and calmodulin-dependent protein kinase IV in the regulation of FMRP by group I metabotropic glutamate receptors. J Neurosci 28:4385-4397. CrossRef Medline

Wei F, Vadakkan KI, Toyoda H, Wu LJ, Zhao MG, Xu H, Shum FW, Jia YH, Zhuo M (2006) Calcium calmodulin-stimulated adenylyl cyclases contribute to activation of extracellular signal-regulated kinase in spinal dorsal horn neurons in adult rats and mice. J Neurosci 26:851-861. CrossRef Medline

Xu H, Wu LJ, Wang H, Zhang X, Vadakkan KI, Kim SS, Steenland HW, Zhuo M (2008) Presynaptic and postsynaptic amplifications of neuropathic pain in the anterior cingulate cortex. J Neurosci 28:7445-7453. CrossRef Medline

Zhao MG, Toyoda H, Lee YS, Wu LJ, Ko SW, Zhang XH, Jia Y, Shum F, Xu H, Li BM, Kaang BK, Zhuo M (2005) Roles of NMDA NR2B subtype receptor in prefrontal long-term potentiation and contextual fear memory. Neuron 47:859-872. CrossRef Medline

Zhong H, Sia GM, Sato TR, Gray NW, Mao T, Khuchua Z, Huganir RL, Svoboda K (2009) Subcellular dynamics of type II PKA in neurons. Neuron 62:363-374. CrossRef Medline

Zhuo M (1998) NMDA receptor-dependent long term hyperalgesia after tail amputation in mice. Eur J Pharmacol 349:211-220. CrossRef Medline

Zhuo M (2008) Cortical excitation and chronic pain. Trends Neurosci 31: 199-207. CrossRef Medline

Zhuo M (2011) Cortical plasticity as a new endpoint measurement for chronic pain. Mol Pain 7:54. CrossRef Medline

Zhuo M (2014) Long-term potentiation in the anterior cingulate cortex and chronic pain. Philos Trans R Soc Lond B Biol Sci 369:20130146. CrossRef Medline 